\title{
CHARACTERIZATION OF SOLID WASTE
}

\section{Dejan Mirakovski ${ }^{1}$ Marija Hadzi-Nikolova ${ }^{1}$ Zoran Despodov $^{1}$ Nikolinka Doneva $^{1}$ Stojance Mijalkovski ${ }^{1}$}

\author{
${ }^{1}$ Faculty of Natural and Technical Sciences, University “Goce Delcev” Stip
}

\begin{abstract}
In order for any community is to formulate an integrated solid waste management program, accurate and reliable data on waste composition and quantities are essential. Such data will encourage well-organized and smoothly functioning recycling programs; foster the optimal design and operation of materials recovery facilities and municipal incinerators; and, ultimately, reduce the amount of waste generated and keep the overall waste management costs low.

In order to apply it more effective strategy for waste management that will be suitable for human health and environmental, practice is to perform classification of waste.

In this paper will be present several protocols for sampling of municipal solid waste (MSW) to determine its composition.
\end{abstract}

\section{INTRODUCTION}

Knowledge of the chemical composition of MSW will guide engineers and scientists of its utility as a fuel and will also help in predicting the makeup of gaseous emissions after incineration as well as of possible hazardous substances occurring in the ash. Waste composition will provide information on the utility of the material for composting or for biological conversion into biogas fuel. In addition, given that the majority of municipal solid waste (MSW) in Republic of Macedonia is disposed of in landfills, knowledge of chemical composition will help in predicting leachate composition and necessary treatment options. The physical properties of MSW will indicate ease of transport, processing requirements, combustion characteristics, and a rough prediction of landfill lifetime.

\section{SAMPLING PROTOCOLS FOR MSW}

MSW consists of a wide range of materials that vary depending on the community and its consumers' income and lifestyles, its degree of industrialization, institutionalism and commercialism. Given these variables, several protocols can be followed to estimate the MSW composition for an area.

In order to compile accurate data, several issues must be addressed (Rhyner et al., 1995):

- How to obtain representative samples of the MSW?

- What is the desired sample size?

- How many samples are needed to achieve a desired level of accuracy? 


\section{Direct Sampling}

Direct sampling is useful on a small scale for obtaining information about MSW composition. The direct sampling method involves physically sampling and sorting MSW at the source of generation. Although MSW can be extremely heterogeneous, direct sampling is one of the more accurate characterization methods. In order to make accurate judgments as to composition, sorting and analysis should be conducted in several randomly selected locations within the community. Waste sampling from single-and multy-family homes, commercial establishments (restaurants and businesses), and institutions (schools, hospitals) is encouraged, as these inputs create local variations.

Another direct sampling approach is to sample the waste after it has arrived at a centralized collection point or a tipping (i.e., unloading) area. This may include a transfer station or disposal facility. ASTM Method D5231-92 (ASTM. 1998) calls for a sample size of 91 to $136 \mathrm{~kg}$ to be manually sorted at the disposal facility. Whether at the source or a disposal facility, the degree of sorting is a function of the number of product categories desired. For example, if a composting program is to be instituted, a sorting scheme might include organic and inorganic materials only. Alternatively, food and yard wastes, the highest quality compost feedstock, can be separated from all other MSW. If a comprehensive materials recovery program is being considered, however, more detailed data about waste categories will be needed-for example; wastes may have to be separated into aluminum, ferrous metals, glass, and paper. In some cases, paper products are further subdivided into old newspaper, old corrugated cardboard, laser-quality office paper, and colored paper.

One disadvantage of direct sampling programs based on a limited number of samples is that data may be misleading if unexpected circumstances occurred during the sampling period. These circumstances could include the delivery of infrequent and exotic wastes, a severe wet or dry season, or errors in sampling methods (U.S.EPA, 1999). Such errors will be compounded when a small number of samples are collected to represent the community waste stream. Sampling studies do not provide accurate information about trends unless they are performed in a consistent manner over a long period of time. Another disadvantage of direct sampling is that it would be prohibitively expensive for making estimates on a national scale.

\section{Material Flows}

Another approach to determining waste composition is to assess material flows. This method is useful for estimating waste stream composition and trends on a regional basis. The U.S. EPA uses materials flow estimation for the compilation of waste data for the United States. The methodology is based on production data (by weight) for materials and products in the waste stream. For a particular municipality, inputs and outputs are recorded and compared. For example, if a community purchases 500000 aluminum beverage cans in 1 week, it can be expected that about 500000 aluminum cans will end up in the waste stream sometime soon 
afterward. This model is, of course, an oversimplification; and one must also consider that the community is an open system having numerous imports and exports (U.S. EPA, 1999).

\section{Surveys}

Waste quantity and composition can be estimated by distributing questionnaires to producers of the waste. This system typically applies to generators of commercial and industrial wastes, and does not work effectively for domestic sources. A questionnaires is distributed to companies in an area, with detailed questions concerning the quantities of waste generated and its composition. Waste types may be listed in relation to product or material categories; for example, a county building may be asked to quantify the laser-quality office paper, mixed, colored papers, ONP, and ONP boxes. Other questions may pertain to seasonal variations in waste generation and any recycling programs already in operation (Williams, 1998). In many cases, however, companies do not maintain accurate records of the amount of waste generated. Data on composition may also be difficult to obtain due to concerns over the release of company and proprietary information.

$\mathrm{Yu}$ and MacLaren (1995) compared the accuracy of direct waste analysis with the survey for determining waste stream composition. Table 1 demonstrates that there is substantial variability in material estimates between the two methods.

Table 1. Waste composition as Estimated by Direct Analysis and Surveys (wt \%)

\begin{tabular}{|c|l|c|c|}
\hline & \multicolumn{1}{|c|}{ Waste type } & Direct Sampling & Survey \\
\hline 1 & Paper & 24.7 & 33.2 \\
\hline 2 & Paperboard & 22.3 & 9.0 \\
\hline 3 & Ferous metals & 5.9 & 3.3 \\
\hline 4 & Nonferrous metals & 0.9 & 0.7 \\
\hline 5 & Plastics & 13.3 & 6.9 \\
\hline 6 & Glass & 2.8 & 8.4 \\
\hline 7 & Rubber & 0.4 & 0.5 \\
\hline 8 & Leather & 0.0 & 0.0 \\
\hline 9 & Textiles & 4.5 & 0.7 \\
\hline 10 & Wood & 7.5 & 10.3 \\
\hline 11 & Vegetation & 1.4 & 0.4 \\
\hline 12 & Fines & 0.3 & 2.2 \\
\hline 13 & Special waste & 0.6 & 0.7 \\
\hline 14 & Construction waste & 4.6 & 2.2 \\
\hline 15 & Food & 10.7 & 20.9 \\
\hline
\end{tabular}

Table 2 demonstrates the estimated quantities of waste generated in Republic of Macedonia. 
Table 2: Estimated quantities of waste generated in RM

\begin{tabular}{|l|c|}
\hline \multicolumn{1}{|c|}{ Type of waste } & Estimated quantity (t / year) \\
\hline Municipal solid waste & 420.000 \\
\hline $\begin{array}{l}\text { Commercial waste (with ingredients similar to those in } \\
\text { the household waste) }\end{array}$ & 150.000 \\
\hline Waste from medical institutions & 1 \\
\hline Construction and demilition waste & 500.000 \\
\hline Industrial non-hazardous waste & 2.120 .000 \\
\hline Industrial hazardous waste & 77.500 \\
\hline Waste from mining & 17.300 .000 \\
\hline Agricultural waste - by-products of animal origin & 4.900 .000 \\
\hline Agricultural waste - by-products of plant origin & 550.000 \\
\hline Old Tires & 5000 \\
\hline Old mineral oils & 8000 \\
\hline Used Cars & 17.500 \\
\hline Old batteries & 3.500 \\
\hline Total & 26.000 .000 \\
\hline
\end{tabular}

Figure 1 demonstrates the municipal solid waste collected from the Eastern Region in Republic of Macedonia in 2008. 


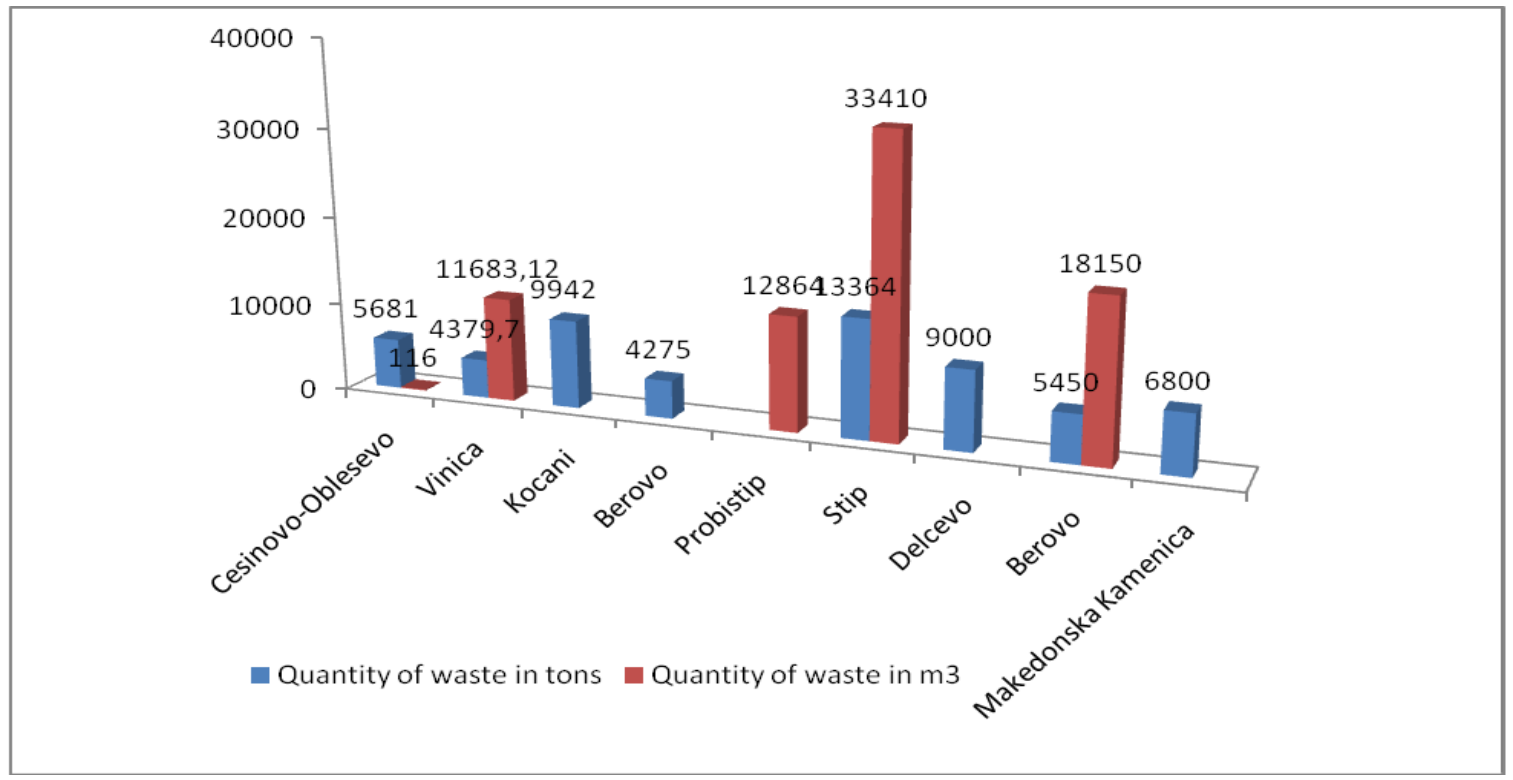

Figure 1. Municipal solid waste collected from the Eastern Region in Republic of Macedonia in 2008

Figure 2 demonstrates the municipal solid waste collected from all regions in Republic of Macedonia in 2008.

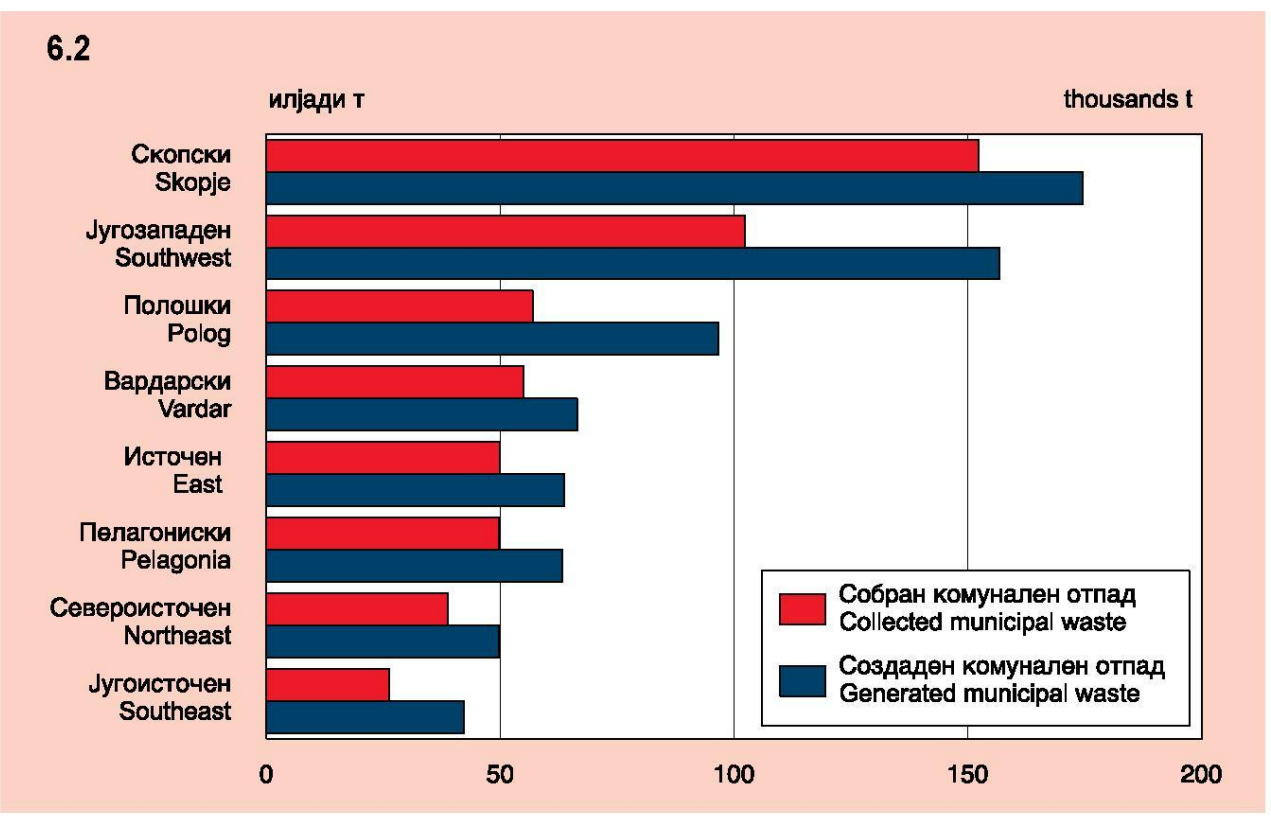

Figure 2. Municipal solid waste collected from all regions in Republic of Macedonia in 2008.

Figure 3 demonstrates the municipal solid waste collected from Southeast Region in Republic of Macedonia in 2008. 


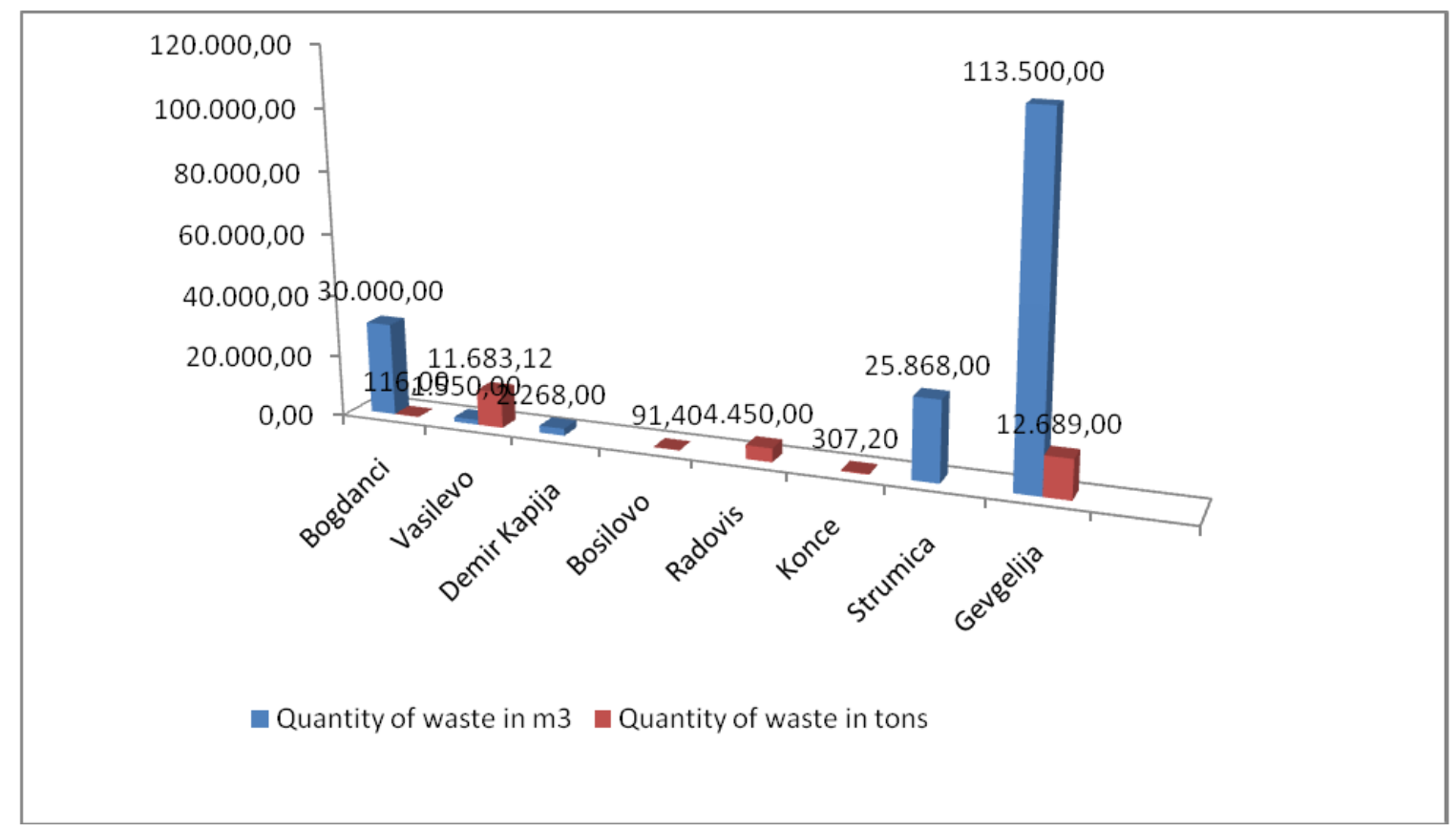

Figure 3. Municipal solid waste collected from Southeast Region in Republic of Macedonia in 2008.

Figure 4 demonstrates the municipal solid waste collected from the Northeastern Region in Republic of Macedonia in 2008.

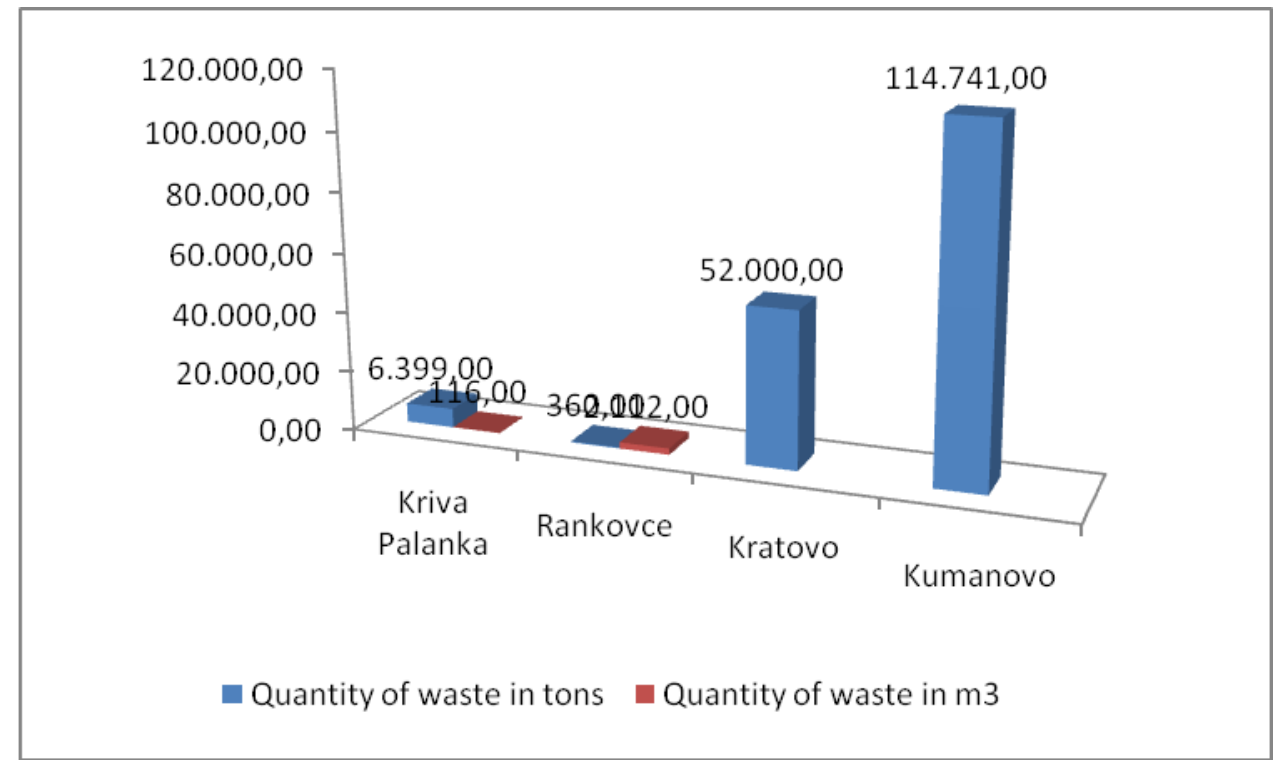

Figure 4. Municipal solid waste collected from the Northeastern Region in Republic of Macedonia in 2008 


\section{Multipliers for Projecting Waste Quantities}

Waste generation multipliers are used for estimating waste quantities from sources in a particular region. These multipliers express the relationship between the amount of waste produced and an identifiable parameter, for example a household or a specific industry. The value of the multiplier is based upon surveys, published data, and direct sampling for an area. For example, for a county in the Midwest US, a household waste multiplier may be derived based on the size of the population. Agricultural multipliers may be formulated based on the number and type of livestock and the total land area available for grazing. Industrial waste multipliers may be based on the number of employees at a facility. The population of the area in question is multiplied by the appropriate value to obtain an estimate of waste production.

Table 3 demonstrates the waste generation rates as a function of generator type.

Table 3. Waste generation rates as a function of generator type

\begin{tabular}{|c|l|c|c|}
\hline & Waste generation sector & Average & Units \\
\hline 1 & Single/family residential & 1,22 & $\mathrm{~kg} /$ person / day \\
\hline 2 & Apartments & 1,14 & $\mathrm{~kg} /$ person / day \\
\hline 3 & Offices & 1,09 & $\mathrm{~kg} /$ person / day \\
\hline 4 & $\begin{array}{l}\text { Eathing and drinking } \\
\text { establishment }\end{array}$ & 6,77 & $\mathrm{~kg} /$ person / day \\
\hline 5 & Whole and retail trade & 0,009 & $\mathrm{~kg} / \$ / \mathrm{sales}$ \\
\hline 6 & Food stores & 0,015 & $\mathrm{~kg} / \$ / \mathrm{sales}$ \\
\hline 7 & Educational facilities & 0,23 & $\mathrm{~kg} / \mathrm{person} /$ day \\
\hline
\end{tabular}

In efforts to develop more accurate waste generation multipliers, some surveys have taken into account numerous factors, including the size of the local population in a region, the type and age of residence occupied, season of the year, and types of businesses in an area. Also useful are economic data such as industrial output and number of employees (Rhyner and Green, 1988; savage, 1996; Williams, 1998).

Household waste generation multipliers have varied wildly. Estimates of household waste production have varied between 1.08 and $1.22 \mathrm{~kg} /$ person/day (Rhyner and Green, 1988). More accurate estimates can be generated for household using multipliers based on the population size of the community. Smaller communities produce a lower waste generation per person per day compared with larger communities (Table 4) (Yu and MacLaren, 1995). 
Table 4. Household waste Multipliers Based on the Community Population Size.

\begin{tabular}{|c|c|}
\hline Population & $\begin{array}{c}\text { Waste generation multiplier } \\
\text { (kg / person / day) }\end{array}$ \\
\hline$<2.500$ & 0.91 \\
\hline $2.500-10.000$ & 1.22 \\
\hline $10.000-30.000$ & 1.45 \\
\hline$>30.000$ & 1.63 \\
\hline
\end{tabular}

The multipliers used for predicting future waste production quantities have significant implications for planning. If waste quantities are expected to increase or if composition is expected to change (e.g., due to the arrival of new businesses or industries), changes may be needed to accommodate the new waste stream, for example, the establishment of a MRF or expansion of a landfill.

\section{CONCLUSION}

Simply rejection of certain materials can be problematic, especially when it comes to materials that can be reused in industrial processes such as metal shavings, paper or plastic feedback bottles. In certain industrialized countries, especially in Europe, plastic bottles are still not clearly defined status, while in developing countries metal shavings, paper and plastic bottles are seen as resources.

Opportunities for reuse of waste (reaches greater and greater value), and potential environmental risk represents criteria that are used to determine the "end-of-life" status of the waste.

Crossing from status of waste in resource status are located in the heart of the complex word "waste cycle". While the flow and exchange of waste became more common, it became necessary to reach clear agreement on the status of various types of waste at the international level.

Of particular importance are the selection of waste and the knowledge of its composition, which can be determined by any of the above mentioned methods of sampling of municipal solid waste. Which of these methods will be applied depends on the several factors.

\section{REFERENCES}

1. Clifford M. Florczak, James E. Roughton, Hazardous Waste Compiliance, 2001

2. Goran Vujic, Upravjanje cvrstim otpadom, Novi Sad, 2009.

3. John Pichtel, Waste Management Practices, 2009.

4. R. E. Hester and R. M. Harrison, Waste Treatment and Disposal, 2005 